\title{
CÁTIONS TROCÁVEIS, CAPACIDADE DE TROCA DE CÁTIONS E SATURAÇÃO POR BASES EM SOLOS BRASILEIROS ADUBADOS COM COMPOSTO DE LIXO URBANO ${ }^{1}$
}

\author{
Cassio Hamilton Abreu Jr. ${ }^{2 *}$; Takashi Muraoka²; Fernando Carvalho Oliveira ${ }^{3}$ \\ ${ }^{2}$ Lab. de Fertilidade do Solo - USP/CENA, C.P. 96 - CEP: 13400-970 - Piracicaba, SP. \\ ${ }^{3} R$. Edú Chaves, 822, São Dimas - CEP: 13416-020 - Piracicaba, SP. \\ *Autor correspondente <cahabreu@cena.usp.br >
}

\begin{abstract}
RESUMO: O uso agrícola do composto de lixo, como fertilizante orgânico, além de melhorar as propriedades do solo, representa uma alternativa importante para gestão de resíduos sólidos domiciliares. Foram estudados os efeitos da aplicação do composto de lixo, proveniente da cidade de São Paulo (Usina de compostagem São Matheus), na dose de $30 \mathrm{~g} \mathrm{dm}^{-3}$ (60 tha $\left.{ }^{-1}\right)$, na presença e ausência de calcário dolomítico e adubos minerais, sobre os teores de cátions trocáveis $\left(\mathrm{K}^{+}, \mathrm{Ca}^{2+}, \mathrm{Mg}^{2+} \mathrm{e} \mathrm{Na}\right)$; a capacidade de troca de cátions (CTC) e a saturação por bases (V\%) de 21 solos ácidos e 5 solos alcalinos. Nos solos alcalinos o calcário foi substituído por gesso. $\mathrm{O}$ experimento foi conduzido em condições de casa de vegetação em delineamento em blocos ao acaso, com parcelas em faixas e três repetições. Nos solos ácidos, a aplicação do composto de lixo promoveu aumentos nos teores trocáveis de potássio, cálcio, magnésio e sódio, em média, de $195 \%$, $200 \%, 86 \%$ e $1200 \%$, e elevação da CTC em $42 \%$, refletindo na V\%, com aumento médio de $39 \%$. Nos solos alcalinos, esses efeitos foram menos pronunciados, refletindo porém, em média, em aumentos da CTC em $8,4 \%$ e da $\mathrm{V} \%$ em $2 \%$. Os maiores efeitos sobre as propriedades químicas avaliadas foram conseqüências das aplicações do composto + adubo + calcário, nos solos ácidos, e do composto + adubo + gesso, nos solos alcalinos. A aplicação agrícola do composto de lixo urbano é viável, porém seus efeitos sobres as propriedades químicas do solo devem ser monitorados.

Palavras-chave: CTC, adubação orgânica, fertilidade do solo

\section{EXCHANGEABLE CATIONS, CATION EXCHANGE CAPACITY AND BASE SATURATION IN BRAZILIAN SOILS AMENDED WITH URBAN WASTE COMPOST}

\begin{abstract}
The use of urban organic solid waste compost as organic fertilizer is an important alternative to solid waste management. This waste has been applied to agricultural lands because of the benefits in relation to soil chemical properties. A greenhouse experiment was conducted to investigate the effects of the application of urban waste compost, at the rate of $30 \mathrm{~g} \mathrm{dm}^{-3}\left(60 \mathrm{tha}^{-1}\right)$, on the contents of exchangeable cations $\left(\mathrm{K}^{+}, \mathrm{Ca}^{2+}\right.$, $\mathrm{Mg}^{2+}$, and $\mathrm{Na}^{+}$), on cation exchangeable capacity (CEC), and on base saturation (BS\%) of 21 acid and 5 alkaline soils. The organic compost (collected at the São Matheus Plant Treatment, São Paulo, Brazil) was applied with or without dolomitic lime and mineral fertilizers. For alkaline soils, lime was substituted by gypsum. The experiment was carried out on a split-plot, completely randomized block design with three replicates. The compost application increased the exchangeable content of potassium, calcium, magnesium, and sodium on average of $195 \%, 200 \%, 86 \%$, and $1200 \%$, respectively, and elevated the CEC by $42 \%$ in acid soils. Consequently the BS\% was increased $39 \%$. A lower, but significant, increase on CEC was observed in alkaline soils in response to the compost application. Average CEC and BS\% increases were of $8.4 \%$ and $2 \%$, respectively. The highest effects on the evaluated soil properties were verified for compost + fertilizer + lime and compost + fertilizer + gypsum applications in acid and alkaline soils, respectively. It is concluded that the use of urban waste compost in agricultural lands is viable only if its effects on chemical properties are properly monitored.
\end{abstract}

Key words: CEC, organic fertilization, soil fertility

\section{INTRODUÇÃO}

A aplicação agronômica do composto de lixo urbano, quando obtido de modo adequado, é viável devido à sua riqueza em matéria orgânica e nutrientes, à ausência de microrganismos patogênicos (Xin et al., 1992; Melo et al., 1997; Cravo et al., 1998) e às melhorias das condições de cultivo do solo (aumento do teor de matéria orgânica, elevação do pH, redução da acidez potencial e aumento da disponibilidade de fósforo, potássio, cálcio e magnésio), da nutrição e produção dos vegetais (Hortenstine \& Rothwell, 1972; Bengston \& Cornette, 1973; Mazur et al., 1983; Kiehl, 1985; Ferro Neto, 1994; Cravo, 1995; Lima et al., 1999; Oliveira, 2000; Abreu Jr. et al., 2000).

${ }^{1}$ Parte da Tese de Doutorado do primeiro autor apresentada à USP/ESALQ - Piracicaba, SP. 
Hortenstine \& Rothwell (1972) e Bengston \& Cornette (1973) observaram aumentos nos teores de potássio, cálcio e magnésio de solos tratados com doses de composto de lixo de até $70 \mathrm{tha}^{-1}$. Trabalho conjunto realizado pela CETESB de Novo Horizonte e a UNESP de Jaboticabal mostrou que a aplicação de $30 \mathrm{t} \mathrm{ha}^{-1}$ de vermicomposto aumentou os teores de potássio em $40 \%$ e de magnésio em 50\% (Ferro Neto, 1994). Cravo (1995) verificou aumento nos teores trocáveis de potássio e de cálcio, em função de doses de composto de até 120 $\mathrm{t}$ ha ${ }^{-1}$, tanto em um solo arenoso quanto em outro argiloso. Porém, o magnésio teve seu teor aumentado somente no solo arenoso.

Em solos de regiões tropicais onde predominam minerais de baixa CTC (argila do tipo 1:1 e sesquióxidos de $\mathrm{Fe}, \mathrm{Al}$ e $\mathrm{Mn}$ ), o manejo de materiais orgânicos (resíduos de culturas, esterco, composto de lixo, lodo de esgoto, etc.) é de fundamental importância por contribuir com até mais de $90 \%$ da CTC do solo (Kiehl, 1985; Melo et al., 1997). As cargas negativas, responsáveis pelo incremento da CTC, são conseqüências dos grupos funcionais carboxílicos $(-\mathrm{COOH})$, fenólicos $(-\mathrm{OH})$, álcoois $(-\mathrm{OH})$ e metoxílicos $\left(-\mathrm{OCH}_{3}\right)$ que se encontram na periferia dos ácidos orgânicos presentes no húmus (Fassbender, 1975) e dependem do pH do solo (Rodela et al., 1995; Benites \& Mendonça, 1998; Oliveira, 2000).

Conforme Hortenstine \& Rothwell (1972), a aplicação de composto de lixo nas doses de 35 e 70 t ha $^{-1}$, em um solo degradado por mineração, promoveu o aumento da CTC de $8,4 \mathrm{mmol}_{\mathrm{c}} \mathrm{kg}^{-1}$ para 13,0 e 20,1 $\mathrm{mmol}_{\mathrm{c}} \mathrm{kg}^{-1}$, respectivamente. Bengtson \& Cornette (1973) verificaram que a aplicação de $44 \mathrm{tha}^{-1}$ de composto em um solo arenoso aumentou a CTC em 18\%. Todavia, a contribuição do composto de lixo na CTC de solos sob clima tropical é baixa, indicando que somente aplicações consecutivas de doses elevadas do composto aumentarão significativamente a CTC desses solos (Berton \& Valadares, 1991; Lima et al., 1999; Oliveira, 2000).

Aplicações sucessivas e em elevadas doses do composto de lixo, todavia, sem o devido monitoramento, podem causar efeitos negativos ao solo e às plantas. $A$ salinização, avaliada pela condutividade elétrica (Abreu Jr. et al., 2000), o acúmulo de metais (Cravo et al., 1998), a lixiviação de nitratos (Oliveira, 2000) e, a dispersão dos colóides e redução da condutividade hidráulica do solo, decorrentes da substituição do cálcio e magnésio da interface solução do solo-superfície coloidal pelo sódio e potássio, presentes em altas concentrações no composto de lixo (Melo et al., 1997), são os principais aspectos ambientais a serem monitorados para o sucesso desta prática.

Outro aspecto importante a ser abordado na adubação com composto de lixo é a necessidade ou não de adubação mineral complementar, visto que para algumas culturas, dependendo do tipo de solo, a aplicação isolada do composto de lixo é insuficiente para garantir o adequado suprimento de nutrientes e da produção (Cravo, 1995).
$O$ presente trabalho teve por objetivo o estudo dos efeitos da aplicação de composto de lixo, na presença e ausência de adubo mineral e de calcário, sobre os teores de cátions trocáveis, a capacidade de troca de cátions e a saturação por bases de solos de diferentes regiões do Brasil.

\section{MATERIAL E MÉTODOS}

Foram utilizadas amostras da camada 0 - 0,2 m de 26 solos representativos de diferentes regiões do Brasil, sendo 21 solos ácidos e 5 solos alcalinos, dos quais 4 solos eram calcários e 1 salino-sódico. As amostras utilizadas no experimento foram secas ao ar, passadas em peneira de $2 \mathrm{~mm}$ de malha, armazenadas em sacos plásticos e analisadas quimicamente conforme descrito em Raij et al. (1987) (TABELA 1).

O composto de lixo foi coletado na usina de compostagem São Matheus, da cidade de São Paulo, SP. Amostras do composto, com aproximadamente quatro meses de compostagem, foram secas ao ar, homogeneizadas e passadas em peneira de $4 \mathrm{~mm}$ de malha. A análise química do composto revelou os seguintes resultados: umidade de $390 \mathrm{~g} \mathrm{~kg}^{-1} ; \mathrm{pH}$ em água (1:4) de 7,96; condutividade elétrica em água (1:1) de $7,25 \mathrm{dS} \mathrm{m}^{-1}$ (a $25^{\circ} \mathrm{C}$ ); teores totais de carbono, nitrogênio, fósforo, potássio, cálcio, magnésio, sódio e alumínio, em g kg${ }^{-1}, 253$; 13,$3 ; 3,1 ; 2,4 ; 28,6 ; 4,1 ; 8,5$ e 20,6 ; respectivamente. 0 carbono total foi determinado pelo método da combustão por via seca empregando-se o auto-analisador de carbono LECO CR-412 (Laboratório de Biogeoquímica do Solo-USP/ CENA), o nitrogênio total pelo método de Kjeldahl, e os demais elementos por espectrometria de emissão atômica com plasma acoplado indutivamente (ICP-AES) (Laboratório de Química Analítica-USP/CENA) em extrato de digestão com $\mathrm{HCl}, \mathrm{HClO}_{4}$ e $\mathrm{HF}$ (Boaventura et al., 1995).

$O$ experimento foi conduzido em condições de casa de vegetação no Centro de Energia Nuclear na Agricultura (USP/CENA), em Piracicaba, SP, utilizando-se vasos plásticos contendo $1,1 \mathrm{dm}^{3}$ de amostra dos diferentes solos. Os tratamentos constituíram-se da aplicação do composto, na dose de $30 \mathrm{~g} \mathrm{dm}^{-3}$ (equivalente a $60 \mathrm{t} \mathrm{ha}^{-1}$ na base de material seco), na presença ou ausência de calcário dolomítico e de adubos minerais. As amostras de terra receberam uma quantidade de calcário dolomítico (PRNT de 104\%) suficiente para elevar a saturação por bases a 70\% (TABELA 1), nos respectivos tratamentos. As amostras dos solos alcalinos receberam $3 \mathrm{~g} \mathrm{dm}^{-3}$ (6 tha-1) de gesso, de acordo com o preconizado por Santos (1995), em substituição ao calcário.

Após um período de incubação de 30 dias, na qual a umidade das amostras dos solos foram mantidas em $60 \%$ da capacidade de retenção de água, com pesagem e rega diária empregando-se água destiladadeionizada; o composto e os adubos minerais foram misturados às amostras de solo, conforme o respectivo tratamento. Os macronutrientes $\mathrm{N}, \mathrm{P}$ e K foram aplicados 
TABELA 1 - Propriedades químicas das amostras dos solos, camada 0-0,2 m, empregadas no experimento.

\begin{tabular}{|c|c|c|c|c|c|c|c|c|c|c|}
\hline (1)Solo & M.O. & $\mathrm{pH}\left(\mathrm{CaCl}_{2}\right)$ & $\mathrm{K}^{+}$ & $\mathrm{Ca}^{2+}$ & $\mathrm{Mg}^{2+}$ & ${ }^{(2)} \mathrm{Na}^{+}$ & $\mathrm{H}^{+}+\mathrm{A}^{\beta+}$ & T & V & ${ }^{(3)} \mathrm{NC}$ \\
\hline & $\mathrm{g} \mathrm{dm}^{-3}$ & & \multicolumn{6}{|c|}{ - } & $-\%-$ & $\mathrm{g} \mathrm{dm}^{-3}$ \\
\hline \multicolumn{11}{|c|}{ Solo ácido } \\
\hline Gleissolo Háplico Tb Distrófico (GX) & 12,7 & 4,56 & 1,45 & 27,2 & 6,8 & 1,1 & 36,2 & 72,6 & 50,1 & 0,69 \\
\hline Neossolo Quartzarênico Distrófico (RQ-1) & 21,7 & 5,52 & 1,13 & 15,9 & 6,8 & 0,3 & 12,8 & 37,0 & 65,4 & 0,08 \\
\hline Latossolo Amarelo Acriférrico (LA-1) & 25,2 & 3,82 & 0,89 & 2,1 & 1,3 & 0,2 & 95,2 & 99,7 & 4,5 & 3,14 \\
\hline Latossolo Vermelho Distroférrico (LV-1) & 22,2 & 5,52 & 2,84 & 26,4 & 14,6 & 0,3 & 21,3 & 65,4 & 67,4 & 0,08 \\
\hline Latossolo Vermelho Acriférrico (LV-2) & 27,4 & 4,10 & 0,78 & 1,2 & 1,1 & 0,2 & 67,3 & 70,6 & 4,7 & 2,22 \\
\hline Latossolo Amarelo Distrófico (LA-2) & 22,9 & 3,78 & 0,71 & 4,8 & 2,2 & 0,5 & 50,8 & 59,2 & 14,2 & 1,59 \\
\hline Argissolo Vermelho-Amare lo Distrófico (PVA-1) & 25,0 & 3,98 & 0,74 & 8,1 & 2,5 & 0,8 & 40,5 & 52,7 & 23,1 & 1,19 \\
\hline Latossolo Amarelo Distrófico (LA-3) & 37,9 & 3,91 & 1,06 & 9,2 & 8,3 & 1,2 & 81,9 & 101,7 & 19,5 & 2,47 \\
\hline Latossolo Amarelo Distrófico (LA-4) & 32,6 & 4,72 & 1,92 & 21,2 & 6,0 & 0,5 & 28,6 & 58,3 & 50,9 & 0,54 \\
\hline Nitossolo Vermelho Distroférrico (NV-1) & 14,9 & 4,64 & 0,99 & 17,1 & 7,0 & 0,3 & 45,2 & 70,6 & 35,9 & 1,16 \\
\hline Latossolo Amarelo Distrófico Argissólico (LA-5) & 19,9 & 4,52 & 2,62 & 15,5 & 3,6 & 0,4 & 30,3 & 52,4 & 42,2 & 0,70 \\
\hline Argissolo Vermelho-Amare lo Distrófico (PVA-2) & 22,4 & 4,54 & 1,32 & 7,9 & 3,6 & 0,2 & 24,6 & 37,7 & 34,8 & 0,64 \\
\hline Latossolo Amarelo Eutrófico Argissólico (LA-6) & 24,1 & 4,58 & 2,13 & 36,3 & 10,6 & 0,8 & 46,7 & 96,5 & 51,6 & 0,85 \\
\hline Argissolo Vermelho-Amare lo Distrófico (PVA-3) & 40,8 & 4,25 & 2,33 & 4,3 & 2,4 & 0,2 & 108,6 & 117,8 & 7,8 & 3,52 \\
\hline Latossolo Vermelho Acriférrico (LV-3) & 30,1 & 4,63 & 1,07 & 13,4 & 8,7 & 0,2 & 41,4 & 64,7 & 36,0 & 1,06 \\
\hline Latossolo Vermelho Distrófico (LV-4) & 27,9 & 4,57 & 3,84 & 16,8 & 10,8 & 0,3 & 51,8 & 83,6 & 37,9 & 1,29 \\
\hline Argissolo Vermelho-Amare lo Distrófico (PVA-4) & 25,1 & 4,28 & 0,74 & 10,3 & 3,5 & 0,3 & 38,3 & 53,1 & 27,8 & 1,08 \\
\hline Nitossolo Vermelho Distrófico (NV-2) & 45,0 & 5,28 & 2,16 & 50,0 & 14,1 & 0,2 & 34,3 & 100,9 & 66,0 & 0,19 \\
\hline Neossolo Quartzarê nico Distrófico (RQ-2) & 17,9 & 3,96 & 0,71 & 1,8 & 0,7 & 1,0 & 43,9 & 48,5 & 9,5 & 1,41 \\
\hline Latossolo Vermelho-Amarelo Distrófico (LVA-1) & 36,1 & 4,43 & 1,95 & 7,9 & 3,3 & 0,6 & 48,1 & 62,1 & 22,5 & 1,42 \\
\hline \multicolumn{11}{|c|}{ Solo alcalino } \\
\hline Cambissolo Háplico $T_{A}$ Eutrófico $(C X-1)$ & 24,0 & 6,06 & 2,47 & 139,8 & 22,5 & 0,2 & 21,7 & 186,8 & 88,4 & ------ \\
\hline Cambissolo Háplico $T_{A}$ Eutrófico Vértico (CX-2) & 32,5 & 7,58 & 1,33 & 412,0 & 20,5 & 1,2 & 9,8 & 445,1 & 97,8 & ------ \\
\hline Latossolo Amarelo Eutrófico (LA-7) & 23,3 & 6,74 & 7,56 & 87,6 & 17,0 & 0,5 & 12,9 & 125,7 & 89,7 & ------ \\
\hline Latossolo Vermelho-Amarelo Eutrófico (LVA-2) & 25,0 & 7,29 & 13,84 & 118,6 & 25,6 & 0,7 & 11,0 & 169,7 & 93,5 & ------ \\
\hline Salino-Sódico (SS) & 24,5 & 7,86 & 2,34 & 166,8 & 40,6 & 43,6 & 7,9 & 270,8 & 97,1 & ------ \\
\hline
\end{tabular}

(1)Sistema brasileiro de classificação de solos (Embrapa, 1999); detalhes sobre a procedência dos solos são apresentados por Abreu Jr. et al. (2000). (2)Sódio extraído com extrator Mehlich-1. Demais análises químicas e cálculos conforme descrito em Raij et al. (1987). ${ }^{(3)}$ Necessidade de calagem.

nas doses de 100, 150 e $100 \mathrm{mg} \mathrm{dm}^{-3}$ (equivalentes a 200,300 e $\left.200 \mathrm{~kg} \mathrm{ha}^{-1}\right)$, nas formas de uréia, superfosfato simples (que também serviu como fonte de enxofre) e cloreto de potássio, e os micronutrientes $B$, $\mathrm{Cu}, \mathrm{Fe}, \mathrm{Mn}, \mathrm{Mo}$ e $\mathrm{Zn}$, na forma de solução nutritiva, nas doses de $1 ; 1 ; 3 ; 2,5 ; 0,05$ e $2,5 \mathrm{mg} \mathrm{dm}^{-3}$ (equivalentes a 2, 2, 6, 5, 0,1 e $5 \mathrm{~kg} \mathrm{ha}^{-1}$ ), respectivamente.

Para comparar os efeitos da aplicação do composto de lixo sobre as propriedades químicas dos solos, com aqueles das práticas convencionais de cultivo, empregou-se de um tratamento baseado exclusivamente nas aplicações de calcário e de adubos minerais, nos solos ácidos, e de gesso e de adubos minerais, nos solos alcalinos.

As amostras dos solos com os tratamentos foram novamente incubadas por mais 30 dias, para se permitir a decomposição e estabilização inicial do material orgânico adicionado ao solo. Após este período de incubação, interrompeu-se a rega, permitiu-se a secagem parcial das amostras dos solos e foi retirado aproximadamente $130 \mathrm{~cm}^{3}$ de terra de cada vaso. As amostras de terra obtidas foram secas ao ar, passadas 
em peneira de $0,5 \mathrm{~mm}$ de malha e submetidas à análise de cálcio $\left(\mathrm{Ca}^{2+}\right)$, magnésio $\left(\mathrm{Mg}^{2+}\right)$ e potássio $\left(\mathrm{K}^{+}\right)$ trocáveis, pelo método da resina de troca iônica, conforme descrito em Raij et al. (1987). Após a determinação do teor de sódio $\left(\mathrm{Na}^{+}\right)$, por fotometria de chama, em extrato de $\mathrm{HCl} 0,05 \mathrm{~mol} \mathrm{~L}-1+\mathrm{H}_{2} \mathrm{SO}_{4} 0,025$ $\mathrm{mol} \mathrm{L}^{-1}$ (Mehlich-1) na relação solo/extrator de 1:5 (v/v), calculou-se a capacidade de troca de cátions (CTC) e a saturação por bases (V\%).

$O$ experimento foi instalado em faixas, em delineamento em blocos ao acaso, com três repetições; porém, na prática, a análise estatística empregada foi semelhante a de um esquema em parcelas subdivididas, considerando os solos como parcelas e os tratamentos como subparcelas, visto que estes modelos se diferenciavam apenas quanto à disposição teórica dos solos em faixas, por se encontrarem em vasos. Para as análises exploratórias dos dados (verificação da homogeneidade de variâncias, da independência de erros e da distribuição normal dos erros) e de correlação utilizou-se o programa SAS/SAS Lab (SAS Institute, 1998) e para as análises de variância e de teste de médias, o programa SANEST (Zonta et al., 1987).

\section{RESULTADOS E DISCUSSÃO}

\section{Cátions trocáveis}

A aplicação do composto de lixo, isoladamente, proporcionou incrementos de 1,05 a $4,22 \mathrm{mmol}_{\mathrm{c}} \mathrm{dm}^{-3}$ nos teores de potássio trocável dos solos ácidos quando comparado com a testemunha (TABELA 2) devido à disponibilidade desse elemento no lixo domiciliar. Não houve diferença entre a aplicação do composto de lixo isolado ou combinado com calcário.

Os teores de potássio nos tratamentos composto e composto + calcário não diferiram ou foram superiores aos da aplicação de calcário com adubo mineral (solos LV-1, LA-4, PVA-2, PVA-3, RQ-2 e LVA-1), provavelmente, em conseqüência da interação entre a relação de equilíbrio iônico, dos íons trocáveis e em solução de $\mathrm{K}^{+}$, de $\mathrm{Ca}^{2+}$ e de $\mathrm{Mg}^{2+}$ (ex.: equação de Gapon) (Raij, 1991), e do teor de potássio e da CTC iniciais de cada um dos solos (TABELA 1). A aplicação do composto com adubo promoveu os maiores teores de potássio em todos os solos, independentemente da aplicação ou não do calcário, decorrente do efeito aditivo desses dois materiais.

A CTC inicial dos solos ácidos (TABELA 1) correlacionou-se negativamente com os incrementos nos teores de potássio trocável promovidos pelos tratamentos composto $\left(-0,57^{p>0,05}\right)$, composto + adubo $\left(-0,49^{\mathrm{p}>0,05}\right)$, composto + calcário $\left(-0,57^{\mathrm{p}>0,05}\right)$, composto + adubo + calcário $\left(-0,57^{\mathrm{p}>0,05}\right)$ e adubo + calcário $\left(-0,63^{\mathrm{p}>0,05}\right)$. Isso concorda com os resultados obtidos e indica que 0 aumento do teor de potássio trocável, seja pela aplicação do composto ou adubo mineral, esteve intimamente relacionado com o poder tampão do solo, que depende do tipo de mineral de argila, teores de argila e matéria orgânica. Quanto maiores a CTC e o teor inicial de potássio, maior o poder tampão, e menores foram os efeitos do composto e do fertilizante potássico sobre o incremento no teor trocável do solo.

Conforme Kiehl (1985), o poder tampão da matéria orgânica do solo se deve aos íons hidrogênio pouco dissociados, que agem no tamponamento contra a presença de substâncias alcalinas, e aos íons $\mathrm{Ca}^{2+}$, $\mathrm{Mg}^{2+}$ e K+, com baixos graus de dissociação na solução do solo, adsorvidos ao húmus, que atuam no tamponamento contra alterações que certas substâncias possam promover. O poder tampão está diretamente relacionado com a CTC dos materiais que constituem a matéria orgânica do solo.

O incremento no teor de potássio trocável dos solos ácidos, exceto nos solos GX e LA-6, foi superior a quantidade teórica total adicionada pelo composto $(1,8$ $\mathrm{mmol}_{\mathrm{c}} \mathrm{dm}^{-3}$ ) (TABELA 2). Isto que revela que a aplicação do composto de lixo disponibilizou parte do potássio não trocável do solo. Fatos semelhantes em diferentes solos do Brasil, sob cultivo, são relatados por Malavolta (1976) e Raij (1991). De acordo com esses autores parece haver relação inversa entre o potássio não trocável, ou de reserva, e a CTC do solo. Pode-se supor que a elevação da CTC do sistema pela carga orgânica do composto cause diminuição no teor não trocável e aumente o potássio trocável, em processo dependente do $\mathrm{pH}$.

Nos solos alcalinos, a aplicação isolada do composto de lixo promoveu teores de potássio trocável equivalentes aos do tratamento gesso + adubo (TABELA 2), mostrando a eficiência do composto no suprimento de potássio também nos solos com este tipo de reação. A aplicação do composto + adubo, na presença ou ausência de gesso, promoveu os maiores incrementos nos teores de potássio trocável, exceto no solo LVA-2, onde os diferentes tratamentos com composto não diferiram entre si em face do elevado teor inicial de potássio (TABELA 1), sugerindo a presença de minerais de potássio. Por esse motivo, também não se observou diferença entre os tratamentos gesso + adubo e testemunha neste solo.

Os resultados obtidos indicam a potencialidade do composto de lixo como fonte de potássio para as plantas. Tal é a relevância desse fato, que Haan (1981) justificou o uso agrícola do composto de lixo por ter observado, em condições de campo, de modo semelhante ao que ocorreu neste trabalho, que o potássio contido no composto tem solubilidade comparável ao do potássio dos fertilizantes minerais. Todavia, Cravo (1995) verificou, em condições de casa de vegetação, a redução do teor de potássio trocável em um solo arenoso adubado com composto e cultivado com alface, indicando a necessidade de adubação potássica no cultivo subsequente. As diferenças de resultados experimentais são decorrentes da composição química 
TABELA 2 - Potássio trocável em solos ácidos adubados com composto de lixo, na presença e ausência de calcário dolomítico e adubos minerais, e em solos alcalinos onde o calcário foi substituído por gesso.

\begin{tabular}{|c|c|c|c|c|c|c|}
\hline \multirow{3}{*}{ Solo } & \multicolumn{4}{|c|}{ Composto de lixo } & \multirow{3}{*}{ Calcário e a dubo } & \multirow{3}{*}{ Testemunha } \\
\hline & \multicolumn{2}{|c|}{ sem calcário } & \multicolumn{2}{|c|}{ com calcário } & & \\
\hline & sem adubo & com adubo & sem adubo & com adubo & & \\
\hline \multicolumn{7}{|c|}{ - } \\
\hline \multicolumn{7}{|c|}{ Solo ácido } \\
\hline GX & $2,63 b^{\ddagger}$ & 3,61 a & $2,29 \mathrm{~b}$ & 3,39 a & $2,56 \mathrm{~b}$ & $1,58 \mathrm{c}$ \\
\hline $\mathrm{RQ}-1$ & $4,97 \mathrm{~b}$ & $6,98 \mathrm{a}$ & $4,82 \mathrm{~b}$ & $6,90 \mathrm{a}$ & $4,49 \mathrm{~b}$ & $1,13 \mathrm{c}$ \\
\hline LA-1 & $4,33 \mathrm{~b}$ & $6,24 a$ & $4,06 \mathrm{~b}$ & $6,04 \mathrm{a}$ & $3,89 \mathrm{~b}$ & $1,11 \mathrm{c}$ \\
\hline LV-1 & 5,98 bc & $7,02 a b$ & $5,55 \mathrm{~cd}$ & $7,77 \mathrm{a}$ & $5,02 d$ & $2,91 \mathrm{e}$ \\
\hline LV-2 & $4,02 \mathrm{~b}$ & $6,64 \mathrm{a}$ & $4,23 \mathrm{~b}$ & $6,42 \mathrm{a}$ & $3,61 \mathrm{~b}$ & $0,76 \mathrm{c}$ \\
\hline LA-2 & $4,32 \mathrm{~b}$ & $7,64 a$ & $4,23 \mathrm{~b}$ & $7,03 \mathrm{a}$ & $3,83 \mathrm{~b}$ & $0,67 \mathrm{c}$ \\
\hline PVA-1 & $4,37 \mathrm{~b}$ & $6,89 a$ & $3,85 \mathrm{~b}$ & $6,39 a$ & $3,87 \mathrm{~b}$ & $0,76 \mathrm{c}$ \\
\hline LA-3 & $4,14 \mathrm{~b}$ & $6,71 \mathrm{a}$ & $3,89 \mathrm{~b}$ & $5,89 a$ & $3,48 \mathrm{~b}$ & $0,95 \mathrm{c}$ \\
\hline LA-4 & $5,50 \mathrm{~b}$ & $7,68 \mathrm{a}$ & $5,32 \mathrm{~b}$ & $6,89 a$ & $4,37 \mathrm{c}$ & $1,72 d$ \\
\hline$N V-1$ & $3,14 \mathrm{~b}$ & $4,77 \mathrm{a}$ & $2,80 \mathrm{~b}$ & $4,72 \mathrm{a}$ & $3,02 \mathrm{~b}$ & $0,97 \mathrm{c}$ \\
\hline LA-5 & $6,21 \mathrm{~b}$ & 9,17 a & $5,99 \mathrm{~b}$ & $8,23 a$ & 5,72 b & $2,32 \mathrm{c}$ \\
\hline PVA-2 & $5,34 \mathrm{~b}$ & $7,64 a$ & $5,28 \mathrm{~b}$ & $7,19 a$ & $4,26 \mathrm{c}$ & $1,43 d$ \\
\hline LA-6 & $3,66 \mathrm{~b}$ & $4,96 \mathrm{a}$ & $3,61 \mathrm{~b}$ & $5,01 \mathrm{a}$ & $3,64 \mathrm{~b}$ & $2,36 \mathrm{c}$ \\
\hline PVA-3 & $4,98 \mathrm{~b}$ & $7,28 \mathrm{a}$ & 4,62 b & $6,20 \mathrm{a}$ & $3,82 \mathrm{c}$ & $2,24 d$ \\
\hline LV-3 & $4,44 \mathrm{~b}$ & $6,95 a$ & $4,39 \mathrm{~b}$ & $6,60 \mathrm{a}$ & $3,77 \mathrm{~b}$ & $1,24 \mathrm{c}$ \\
\hline LV -4 & $5,69 \mathrm{~b}$ & $8,53 a$ & $5,74 \mathrm{~b}$ & $8,26 \mathrm{a}$ & $5,39 \mathrm{~b}$ & $3,83 \mathrm{c}$ \\
\hline PV & $2,97 \mathrm{~b}$ & $5,24 a$ & $3,04 \mathrm{~b}$ & $4,83 \mathrm{a}$ & $2,99 \mathrm{~b}$ & $0,67 \mathrm{c}$ \\
\hline PVA-4 & $4,19 \mathrm{~b}$ & $6,57 \mathrm{a}$ & $4,32 \mathrm{~b}$ & $6,34 \mathrm{a}$ & $3,94 \mathrm{~b}$ & $0,78 \mathrm{c}$ \\
\hline NV-2 & $4,70 \mathrm{~b}$ & $6,30 \mathrm{a}$ & $4,67 \mathrm{~b}$ & $6,24 a$ & $4,25 \mathrm{~b}$ & $2,19 \mathrm{c}$ \\
\hline $\mathrm{RQ}-2$ & $5,14 \mathrm{~b}$ & $8,04 \mathrm{a}$ & $4,81 \mathrm{bc}$ & $7,60 \mathrm{a}$ & $4,12 \mathrm{c}$ & $0,92 d$ \\
\hline LVA-1 & $5,28 \mathrm{~b}$ & $7,92 \mathrm{a}$ & $5,49 \mathrm{~b}$ & $6,95 \mathrm{a}$ & $4,15 \mathrm{c}$ & $1,91 \mathrm{~d}$ \\
\hline \multicolumn{7}{|c|}{ (\#)Solo alcalino } \\
\hline$C X-1$ & $3,16 \mathrm{~b}$ & $4,30 \mathrm{a}$ & $2,90 \mathrm{~b}$ & $4,31 \mathrm{a}$ & $2,76 \mathrm{~b}$ & $1,84 \mathrm{c}$ \\
\hline CX-2 & $1,81 \mathrm{~b}$ & $2,68 \mathrm{a}$ & $1,75 b$ & $2,51 \mathrm{a}$ & $1,74 \mathrm{~b}$ & $0,99 \mathrm{c}$ \\
\hline LA-7 & $7,98 \mathrm{bc}$ & $10,25 a$ & $7,81 \mathrm{bc}$ & 9,96 a & $8,43 \mathrm{~b}$ & $7,03 \mathrm{c}$ \\
\hline LVA-2 & $13,50 a b$ & $14,82 \mathrm{a}$ & $13,36 a b$ & $14,80 \mathrm{a}$ & $12,32 \mathrm{bc}$ & $11,60 \mathrm{c}$ \\
\hline SS & $3,45 b$ & $5,10 a$ & $3,54 \mathrm{~b}$ & $4,55 \mathrm{a}$ & $3,53 \mathrm{~b}$ & $2,00 \mathrm{c}$ \\
\hline
\end{tabular}

(‡)Médias seguidas de mesma letra, nas linhas, não diferem pelo teste de Tukey a $5 \%$. ${ }^{(\#)}$ Nos solos alcalinos o calcário foi substituído por gesso.

do composto, de sua aplicação sucessiva ou não e do volume de terra a ser explorado pelas plantas em experimentos com vasos.

Nos solos ácidos, os teores trocáveis de cálcio (TABELA 3) foram aumentados de $41 \%$ (solo NV-2) a $2230 \%$ (solo LV-2) e os de magnésio (TABELA 4) de $5 \%$ (solo NV-2) a $483 \%$ solo (LA-1) devido à aplicação isolada do composto de lixo, promovendo uma relação $\mathrm{Ca} / \mathrm{Mg}$ ampla nesses solos. O maior efeito do composto sobre o cálcio trocável do solo, em detrimento do magnésio, foi decorrente de sua própria composição química $\left(28,6 \mathrm{~g} \mathrm{~kg}^{-1}\right.$ ou $1,43 \mathrm{~mol}_{\mathrm{c}} \mathrm{kg}^{-1}$ de Ca e $4,1 \mathrm{~g} \mathrm{~kg}^{-1}$ ou $0,34 \mathrm{~mol}_{\mathrm{c}} \mathrm{kg}^{-1}$ de $\mathrm{Mg}$ ) e a amplitude de variação dos resultados foi conseqüência dos teores iniciais de cálcio e magnésio trocável, assim como da CTC, que reflete o poder tampão, e acidez potencial nos diferentes solos (TABELA 1).

O efeito da aplicação isolada do composto de lixo sobre a disponibilidade do cálcio e magnésio foi inferior ou semelhante aos efeitos dos tratamentos composto + calcário e calcário + adubo, que de um modo geral foram semelhantes entre si (TABELAS 3 e 4) em conseqüência do maior fornecimento de cálcio e de magnésio pela dolomita. Embora as diferenças entre os efeitos desses dois últimos tratamentos contendo calcário e as destes com o efeito do composto, quanto à disponibilidade do cálcio e magnésio, estejam associadas às propriedades químicas inicias dos solos, elas foram predominantemente causadas pelas diferentes doses de aplicação do calcário (TABELA 1). Abreu Jr. et al. (2000) verificaram, em condições de casa de vegetação, que a aplicação de $30 \mathrm{~g} \mathrm{dm}^{-3}\left(60 \mathrm{tha}^{-1}\right)$ de composto de lixo apresentou efeito sobre o $\mathrm{pH}$ do solo equivalente ao da aplicação de aproximadamente $1 \mathrm{~g} \mathrm{dm}^{-3}\left(2 \mathrm{t} \mathrm{ha}^{-1}\right)$ de calcário.

Os maiores teores de cálcio e magnésio trocável foram observados no tratamento com composto + calcário + adubo (TABELAS 3 e 4) pelo efeito aditivo dos 
materiais. Em nove solos ácidos, os teores de cálcio (TABELA 3) não diferiram entre os tratamentos composto + adubo e composto + calcário + adubo devido à menor dose de calcário (TABELA 1) e do cálcio fornecido pelo superfosfato simples.

Os teores de magnésio trocável (TABELA 4) foram semelhantes nos tratamentos com composto + calcário e composto + calcário + adubação, visto que o adubo mineral não alterou o teor trocável do nutriente. Os efeitos desses tratamentos foram superiores aos da aplicação de calcário + adubo (exceto nos solos LV-2, PVA-1, NV-2 e $R Q-2)$, evidenciando também os benefícios do composto de lixo sobre a disponibilidade de magnésio. O fornecimento de cálcio pelo superfosfato simples foi a causa de relações $\mathrm{Ca} / \mathrm{Mg}$ mais amplas nos tratamentos que receberam adubação mineral.

Os solos alcalinos, de um modo geral, não tiveram os seus teores de cálcio e magnésio trocável modificados pela aplicação do composto de lixo, exceto nos solos LA-7 e SS onde houve efeito para o cálcio (TABELA 3) e no CX-2 para o magnésio (TABELA 4). A ausência de efeito do composto foi conseqüência dos altos valores de $\mathrm{pH}(6,0-6,5)$ nos tratamentos que receberam este resíduo (Abreu Jr. et al., 2000), que conferem baixa solubilidade ao cálcio e ao magnésio, e dos elevados teores iniciais de cálcio e magnésio trocável, e da alta CTC (TABELA 1) que atribuem forte poder tampão a esses solos.

Os efeitos mais significativos dos diferentes tratamentos sobre os teores de cálcio e, consequentemente, da ampliação da relação $\mathrm{Ca} / \mathrm{Mg}$ foram causados pelo gesso. Conforme Santos \& Muraoka (1997), as reações físico-químicas desencadeadas pelas aplicações de gesso, de composto e de qualquer outro corretivo da alcalinidade são profundamente diferentes entre solos calcários (ex.: CX-1, CX-2, LA-7 e LVA-2) e salinos-sódicos (SS) em face de suas características intrínsecas.

TABELA 3 - Cálcio trocável em solos ácidos adubados com composto de lixo, na presença e ausência de calcário dolomítico e adubos minerais, e em solos alcalinos onde o calcário foi substituído por gesso.

\begin{tabular}{|c|c|c|c|c|c|c|}
\hline \multirow{3}{*}{ Solo } & \multicolumn{4}{|c|}{ Composto de lixo } & \multirow{3}{*}{ Calcário e adubo } & \multirow{3}{*}{ Testemunha } \\
\hline & \multicolumn{2}{|c|}{ sem calcário } & \multicolumn{2}{|c|}{ com calcário } & & \\
\hline & sem adubo & com adubo & sem adubo & com adubo & & \\
\hline \multicolumn{7}{|c|}{ 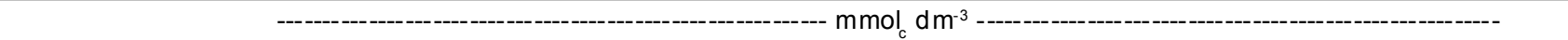 } \\
\hline \multicolumn{7}{|c|}{ Solo ácido } \\
\hline GX & $97,8 b^{\ddagger}$ & 123,9 a & $109,7 \mathrm{ab}$ & 124,6 a & $95,1 \mathrm{~b}$ & $29,6 \mathrm{c}$ \\
\hline $\mathrm{RQ}-1$ & $40,9 \mathrm{~b}$ & $70,1 \mathrm{a}$ & $41,0 \mathrm{~b}$ & $66,3 \mathrm{a}$ & $44,9 \mathrm{~b}$ & $17,9 \mathrm{c}$ \\
\hline LA-1 & $31,5 \mathrm{~d}$ & $54,7 \mathrm{c}$ & $69,5 \mathrm{~b}$ & $88,0 \mathrm{a}$ & $67,7 \mathrm{~b}$ & $1,9 \mathrm{e}$ \\
\hline LV-1 & $53,8 \mathrm{~b}$ & $72,1 \mathrm{a}$ & 58,4 b & $84,7 \mathrm{a}$ & $56,0 \mathrm{~b}$ & $25,8 \mathrm{c}$ \\
\hline LV-2 & $30,3 \mathrm{~d}$ & $56,6 \mathrm{c}$ & $56,9 \mathrm{c}$ & 113,5 a & $81,1 \mathrm{~b}$ & $1,3 \mathrm{e}$ \\
\hline LA-2 & $34,8 \mathrm{c}$ & 65,8 a & $47,6 \mathrm{~b}$ & $70,2 \mathrm{a}$ & $46,1 \mathrm{~b}$ & $3,9 \mathrm{~d}$ \\
\hline PVA-1 & $37,3 \mathrm{~d}$ & $63,4 \mathrm{~b}$ & $47,8 \mathrm{c}$ & $86,1 \mathrm{a}$ & $52,2 \mathrm{c}$ & $8,1 \mathrm{e}$ \\
\hline LA-3 & $32,7 \mathrm{c}$ & $52,0 \mathrm{~b}$ & $58,5 \mathrm{~b}$ & $82,8 \mathrm{a}$ & $60,2 \mathrm{~b}$ & $8,2 \mathrm{~d}$ \\
\hline LA-4 & $44,4 \mathrm{~b}$ & 62,9 a & $51,7 \mathrm{~b}$ & $74,4 \mathrm{a}$ & $48,0 \mathrm{~b}$ & $19,5 \mathrm{c}$ \\
\hline$N V-1$ & $50,8 \mathrm{c}$ & $87,9 \mathrm{~b}$ & $81,3 b$ & 113,9 a & $76,7 \mathrm{~b}$ & $23,9 \mathrm{~d}$ \\
\hline LA-5 & $44,6 \mathrm{c}$ & $72,7 \mathrm{a}$ & $54,7 \mathrm{~b}$ & 83,9 a & $55,1 \mathrm{~b}$ & $11,4 \mathrm{~d}$ \\
\hline PVA-2 & $38,9 \mathrm{~b}$ & $64,9 \mathrm{a}$ & $46,6 \mathrm{~b}$ & $70,6 \mathrm{a}$ & $39,9 \mathrm{~b}$ & $7,3 \mathrm{c}$ \\
\hline LA-6 & $91,1 \mathrm{bc}$ & $105,8 \mathrm{~b}$ & $106,3 b$ & $125,4 \mathrm{a}$ & $86,0 \mathrm{c}$ & $29,3 d$ \\
\hline PVA-3 & $38,3 \mathrm{c}$ & $69,0 \mathrm{~b}$ & $83,1 \mathrm{a}$ & $93,3 \mathrm{a}$ & $68,5 b$ & $4,3 d$ \\
\hline LV-3 & $41,1 \mathrm{c}$ & $62,4 \mathrm{a}$ & $51,8 \mathrm{~b}$ & $63,9 \mathrm{a}$ & $42,5 \mathrm{c}$ & $9,5 \mathrm{~d}$ \\
\hline LV-4 & $47,9 \mathrm{c}$ & $56,5 \mathrm{bc}$ & $63,9 a b$ & $72,0 \mathrm{a}$ & $49,4 \mathrm{c}$ & $17,2 \mathrm{~d}$ \\
\hline PV & $50,6 \mathrm{c}$ & $87,5 \mathrm{a}$ & $71,5 \mathrm{~b}$ & $92,8 \mathrm{a}$ & $71,0 \mathrm{~b}$ & $23,4 d$ \\
\hline PVA-4 & $36,6 \mathrm{~d}$ & $58,8 \mathrm{~b}$ & $48,4 \mathrm{c}$ & $70,6 \mathrm{a}$ & $45,7 \mathrm{c}$ & $10,1 \mathrm{e}$ \\
\hline NV-2 & $85,5 \mathrm{c}$ & $103,5 \mathrm{~b}$ & $86,8 \mathrm{c}$ & 120,5 a & $95,4 \mathrm{bc}$ & $61,0 \mathrm{e}$ \\
\hline $\mathrm{RQ}-2$ & $29,9 \mathrm{c}$ & $36,7 \mathrm{bc}$ & $35,7 \mathrm{bc}$ & $84,4 \mathrm{a}$ & $41,0 \mathrm{~b}$ & $1,5 \mathrm{~d}$ \\
\hline LVA-1 & $30,3 d$ & $52,0 \mathrm{~b}$ & $46,4 \mathrm{~b}$ & 63,3 a & $37,9 \mathrm{c}$ & $4,4 \mathrm{e}$ \\
\hline \multicolumn{7}{|c|}{ (\#)Solo alcalino } \\
\hline$C X-1$ & $151,0 \mathrm{c}$ & $166,9 \mathrm{~b}$ & 198,5 a & 190,3 a & $188,5 \mathrm{a}$ & $153,9 \mathrm{bc}$ \\
\hline$C X-2$ & 444,6 a & $468,3 \mathrm{a}$ & $474,7 \mathrm{a}$ & $482,3 \mathrm{a}$ & $398,5 \mathrm{a}$ & $417,1 \mathrm{a}$ \\
\hline LA-7 & $125,6 \mathrm{c}$ & $134,3 \mathrm{c}$ & $150,5 \mathrm{~b}$ & 167,3 a & $146,5 \mathrm{~b}$ & $109,4 d$ \\
\hline LVA-2 & $142,3 \mathrm{c}$ & $144,8 \mathrm{c}$ & $175,5 a$ & 187,3 a & $158,5 \mathrm{~b}$ & $135,3 \mathrm{c}$ \\
\hline SS & 175,2 b & $179,1 \mathrm{~b}$ & $211,8 \mathrm{a}$ & $212,7 \mathrm{a}$ & 211,6 a & $148,7 \mathrm{c}$ \\
\hline
\end{tabular}

(‡)Médias seguidas de mesma letra, nas linhas, não diferem pelo teste de Tukey a $5 \%$. (\#)Nos solos alcalinos o calcário foi substituído por gesso. 
A relação $\mathrm{K} / \mathrm{Mg}$ do solo, que quando elevada pode induzir a deficiência de $\mathrm{Mg}$ nas plantas pelo excesso de K, variou de 0,07 a 1,5 nos solos ácidos e de 0,05 a 0,49 nos solos alcalinos, indicando que a aplicação do composto causou relações estreitas nestes e muito amplas naqueles solos ácidos. De acordo com Malavolta (1976), para a maioria das culturas intensivas, a deficiência de $\mathrm{Mg}$ seja causada mais freqüentemente por condições adversas do solo ou, então, por falta real de $\mathrm{Mg}$ do que por relação $\mathrm{K} / \mathrm{Mg}$ muito ampla, exceto sob condição de adubação potássica pesada e sucessiva devido ao aumento anormal do teor de $\mathrm{K}$ no solo.

O efeito do composto de lixo urbano sobre os teores de $\mathrm{K}, \mathrm{Ca}$ e $\mathrm{Mg}$ do solo pode variar em função da procedência, do modo de produção deste material e do número de cultivos (Cravo, 1995). Aumentos nos teores de $\mathrm{K}, \mathrm{Ca}$ e $\mathrm{Mg}$ no solo devido à aplicação de composto foram observados por Hortenstine \& Rothwell (1972), Ferro Neto (1994), Cravo (1995) e Trindade et al. (1996).

A aplicação do composto, com ou sem calcário e adubo nos solos ácidos e com ou sem gesso e adubo nos solos alcalinos, aumentou os teores de sódio trocável da ordem de 7 a $10 \mathrm{mmol}^{\mathrm{kg}^{-1}}$ (TABELA 5), em conseqüência do alto teor desse elemento no lixo domiciliar, exceto no solo SS, cujo teor inicial de $\mathrm{Na}^{+}$já era elevado $\left(40,5 \mathrm{mmol}^{-3} \mathrm{dm}^{-3}\right)$. Excluindo-se os solos ácidos GX, LA-3, LA-6 e LV-3, a aplicação de calcário + adubo e de gesso + adubo, no solo alcalino LA-7, promoveram elevação nos teores de sódio da ordem de 0,5 a $0,8 \mathrm{mmol}_{\mathrm{c}} \mathrm{kg}^{-1}$.

Uma das principais implicações dos aumentos nos teores $\mathrm{K}^{+}, \mathrm{Ca}^{2+}, \mathrm{Mg}^{2+}$ e $\mathrm{Na}^{+}$é a possibilidade da ocorrência de salinização do solo. Melo et al. (1997) explicam que a aplicação, ao solo, de composto rico em sódio e potássio pode promover o aumento dos teores

TABELA 4 - Magnésio trocável em solos ácidos adubados com composto de lixo, na presença e ausência de calcário dolomítico e adubos minerais, e em solos alcalinos onde o calcário foi substituído por gesso.

\begin{tabular}{|c|c|c|c|c|c|c|}
\hline \multirow{3}{*}{ Solo } & \multicolumn{4}{|c|}{ Composto de lixo } & \multirow{3}{*}{ Calcário e adubo } & \multirow{3}{*}{ Testemunha } \\
\hline & \multicolumn{2}{|c|}{ sem calcário } & \multicolumn{2}{|c|}{ com calcário } & & \\
\hline & sem adubo & com adubo & sem adubo & com adubo & & \\
\hline & \multicolumn{6}{|c|}{$\begin{array}{l} \\
\end{array}$} \\
\hline \multicolumn{7}{|c|}{ Solo ácido } \\
\hline GX & $27,5 c^{\ddagger}$ & $28,2 \mathrm{bc}$ & 31,4 a & $30,8 \mathrm{ab}$ & $26,0 \mathrm{c}$ & $10,3 d$ \\
\hline RQ-1 & $12,1 \mathrm{a}$ & $12,6 \mathrm{a}$ & $12,6 a$ & $13,2 a$ & $9,6 \mathrm{~b}$ & $9,3 \mathrm{~b}$ \\
\hline LA-1 & $7,0 \mathrm{~b}$ & $6,9 \mathrm{~b}$ & $24,3 a$ & $22,6 \mathrm{a}$ & $22,2 \mathrm{a}$ & $1,2 \mathrm{c}$ \\
\hline LV-1 & $21,2 a b$ & $19,9 \mathrm{~b}$ & $21,9 a b$ & $23,1 \mathrm{a}$ & $19,9 \mathrm{~b}$ & $16,2 \mathrm{c}$ \\
\hline LV-2 & $6,2 \mathrm{~d}$ & $6,5 \mathrm{~d}$ & $18,6 \mathrm{c}$ & $25,2 \mathrm{a}$ & $22,6 \mathrm{~b}$ & $1,1 \mathrm{e}$ \\
\hline LA-2 & $8,3 \mathrm{c}$ & $9,7 \mathrm{c}$ & $17,1 \mathrm{a}$ & $17,4 \mathrm{a}$ & $13,6 \mathrm{~b}$ & $2,2 d$ \\
\hline PVA-1 & $8,7 \mathrm{~d}$ & $8,4 \mathrm{~d}$ & $14,5 \mathrm{~b}$ & $17,2 \mathrm{a}$ & $12,5 \mathrm{c}$ & $3,0 \mathrm{e}$ \\
\hline LA-3 & $12,2 \mathrm{~b}$ & $13,0 \mathrm{~b}$ & 26,4 a & $25,9 a$ & $24,0 \mathrm{a}$ & $8,5 \mathrm{c}$ \\
\hline LA-4 & $11,4 \mathrm{~b}$ & $11,3 \mathrm{~b}$ & 14,6 a & $15,1 \mathrm{a}$ & $11,6 \mathrm{~b}$ & $6,7 \mathrm{c}$ \\
\hline$N V-1$ & $16,0 \mathrm{~d}$ & $18,5 \mathrm{c}$ & $26,7 \mathrm{a}$ & $28,3 a$ & $22,9 \mathrm{~b}$ & $9,6 \mathrm{e}$ \\
\hline LA-5 & $9,7 \mathrm{~b}$ & $10,4 \mathrm{~b}$ & $14,4 \mathrm{a}$ & $14,8 \mathrm{a}$ & $10,8 \mathrm{~b}$ & $3,3 c$ \\
\hline PVA-2 & $10,9 \mathrm{~b}$ & $11,1 \mathrm{~b}$ & $14,4 a$ & $14,5 \mathrm{a}$ & $10,7 \mathrm{~b}$ & $5,0 \mathrm{c}$ \\
\hline LA-6 & $28,9 \mathrm{~b}$ & $26,7 \mathrm{~b}$ & $33,1 \mathrm{a}$ & $32,5 \mathrm{a}$ & $27,2 \mathrm{~b}$ & $11,7 \mathrm{c}$ \\
\hline PVA-3 & $9,0 \mathrm{c}$ & $10,4 \mathrm{c}$ & $30,7 \mathrm{a}$ & $26,7 \mathrm{~b}$ & $25,6 \mathrm{~b}$ & $2,9 d$ \\
\hline LV-3 & $15,4 \mathrm{c}$ & $15,3 \mathrm{c}$ & 20,6 a & $18,9 a b$ & $16,8 \mathrm{bc}$ & $9,2 \mathrm{~d}$ \\
\hline LV-4 & $19,0 \mathrm{c}$ & $18,3 \mathrm{c}$ & $26,9 a$ & $26,0 a b$ & $24,2 b$ & $12,8 d$ \\
\hline PV & $15,4 \mathrm{c}$ & $18,6 \mathrm{~b}$ & $23,7 a$ & $22,5 \mathrm{a}$ & $19,8 \mathrm{~b}$ & $10,0 d$ \\
\hline PVA-4 & $8,7 \mathrm{c}$ & $9,2 \mathrm{c}$ & $14,5 \mathrm{a}$ & $14,8 \mathrm{a}$ & $12,0 \mathrm{~b}$ & $3,8 d$ \\
\hline$N V-2$ & $23,6 \mathrm{bc}$ & $22,7 \mathrm{bc}$ & $24,1 \mathrm{bc}$ & $27,5 \mathrm{a}$ & $25,0 a b$ & $22,4 \mathrm{c}$ \\
\hline RQ-2 & $6,3 c$ & $6,0 \mathrm{c}$ & $11,7 \mathrm{~b}$ & $16,0 \mathrm{a}$ & $12,1 \mathrm{~b}$ & $1,2 \mathrm{~d}$ \\
\hline LVA-1 & $8,2 \mathrm{c}$ & $8,9 \mathrm{c}$ & $17,0 \mathrm{a}$ & $16,0 \mathrm{a}$ & $12,8 \mathrm{~b}$ & $3,1 \mathrm{~d}$ \\
\hline \multicolumn{7}{|c|}{ (\#)Solo alcalino } \\
\hline CX-1 & $25,3 \mathrm{~b}$ & $26,6 a b$ & $28,9 a$ & $26,5 a b$ & $25,9 \mathrm{~b}$ & $26,2 \mathrm{~b}$ \\
\hline CX-2 & 26,8 a & $24,4 \mathrm{~b}$ & $22,8 \mathrm{bc}$ & $23,5 \mathrm{bc}$ & $21,6 \mathrm{~cd}$ & $20,5 d$ \\
\hline LA-7 & $22,4 a b$ & $22,5 a b$ & $24,2 \mathrm{a}$ & $24,0 \mathrm{a}$ & $21,1 \mathrm{~b}$ & $21,0 \mathrm{~b}$ \\
\hline LVA-2 & $32,0 a b$ & $30,2 \mathrm{bc}$ & $33,0 a b$ & $33,4 a$ & $28,8 \mathrm{c}$ & $32,4 a b$ \\
\hline SS & 44,7 bc & $41,9 \mathrm{c}$ & $50,3 a$ & $48,9 a b$ & $45,5 a b c$ & $41,8 \mathrm{c}$ \\
\hline
\end{tabular}

(‡) Médias seguidas de mesma letra, nas linhas, não diferem pelo teste de Tukey a $5 \%$. (\#) Nos solos alcalinos o calcário foi substituído por gesso. 
destes elementos na solução do solo, seguindo-se com o aumento da condutividade elétrica, o deslocamento de cálcio e magnésio adsorvidos no complexo de troca e a dispersão dos colóides. Para Oliveira (2000), tais problemas podem ser agravados em casos de aplicações sucessivas de composto de lixo em regiões com baixos índices pluviométricos. A elevada adição de $\mathrm{Na}^{+}$poderá conduzir à sodicidade.

Em solos sódicos e salino-sódicos, conforme Avnimelech et al. (1990,1994), a aplicação de composto de lixo reduz a concentração excessiva de sais pelo aumento da CTC e pela complexação de íons metálicos por ácidos orgânicos liberados no processo de decomposição do material orgânico contido no resíduo. O processo de complexação favorece a lixiviação dos sais em excesso após irrigação. Segundo esses autores, a melhoria dos atributos físicos, químicos e da produtividade agrícola devido ao composto foi semelhante ou até mesmo superior à do gesso.
Os efeitos dos tratamentos sobre os teores dos cátions trocáveis nos solos alcalinos foram decorrentes principalmente da interação de seus efeitos sobre o $\mathrm{pH}$ (Abreu Jr. et al., 2000) com as propriedades químicas iniciais desses solos (TABELA 1). Conforme apresentado por Santos \& Muraoka (1997), o acúmulo de $\mathrm{Ca}^{2+}, \mathrm{Mg}^{2+}$, $\mathrm{K}^{+}$e $\mathrm{Na}^{+}$nos solos CX-1, CX-2, LA-7 e LVA-2, considerando-os como salinos, deve estar associado ao abaixamento do $\mathrm{pH}$, enquanto que no solo SS, considerando-o como sódico, o acúmulo de sais ligados aos íons carbonatos e bicarbonatos deve estar associado ao aumento do $\mathrm{pH}$.

Capacidade de troca de cátions e saturação por bases

A aplicação isolada do composto de lixo nos solos ácidos promoveu a elevação da CTC de $7 \%$ a 117 \% (TABELA 6). Todavia, não se observou diferenças significativas entre esse tratamento e a testemunha dos solos LA-1 e PVA-3 em virtude da elevada acidez potencial inicial desses solos (TABELA 1); dos valores de

TABELA 5 - Sódio trocável em solos ácidos adubados com composto de lixo, na presença e ausência de calcário dolomítico adubos minerais, e em solos alcalinos onde o calcário foi substituído por gesso.

\begin{tabular}{|c|c|c|c|c|c|c|}
\hline \multirow{3}{*}{ Solo } & \multicolumn{4}{|c|}{ Composto de lixo } & \multirow{3}{*}{ Calcário e adubo } & \multirow{3}{*}{ Testemunha } \\
\hline & \multicolumn{2}{|c|}{ sem calcário } & \multicolumn{2}{|c|}{ com calcário } & & \\
\hline & sem adubo & com adubo & sem adubo & com adubo & & \\
\hline & \multicolumn{6}{|c|}{ - --- } \\
\hline \multicolumn{7}{|c|}{ Solo ácido } \\
\hline GX & $10,0 \mathrm{a}^{\ddagger}$ & $9,2 \mathrm{a}$ & $10,2 \mathrm{a}$ & $8,7 \mathrm{a}$ & $2,1 \mathrm{~b}$ & $1,8 \mathrm{~b}$ \\
\hline $\mathrm{RQ}-1$ & $8,6 \mathrm{a}$ & $8,3 a$ & $8,0 \mathrm{a}$ & $7,9 \mathrm{a}$ & $1,3 b$ & $0,3 \mathrm{c}$ \\
\hline LA-1 & $8,9 a$ & $8,2 \mathrm{a}$ & $8,0 \mathrm{a}$ & $8,2 \mathrm{a}$ & $1,2 \mathrm{~b}$ & $0,5 \mathrm{c}$ \\
\hline LV-1 & $9,2 \mathrm{a}$ & $7,1 \mathrm{~b}$ & $7,6 a b$ & $8,4 a b$ & $1,0 \mathrm{c}$ & $0,3 d$ \\
\hline LV-2 & $7,3 \mathrm{a}$ & $8,0 \mathrm{a}$ & $7,2 \mathrm{a}$ & $7,2 \mathrm{a}$ & $1,0 \mathrm{~b}$ & $0,5 \mathrm{c}$ \\
\hline LA-2 & $9,1 \mathrm{a}$ & $10,2 \mathrm{a}$ & $8,8 \mathrm{a}$ & $9,7 \mathrm{a}$ & $1,3 b$ & $0,7 \mathrm{c}$ \\
\hline PVA-1 & $9,7 \mathrm{a}$ & $8,7 \mathrm{a}$ & $8,0 \mathrm{a}$ & $8,5 \mathrm{a}$ & $1,7 \mathrm{~b}$ & $0,8 \mathrm{c}$ \\
\hline LA-3 & $8,8 \mathrm{a}$ & $8,8 \mathrm{a}$ & $8,6 \mathrm{a}$ & $8,8 \mathrm{a}$ & $1,9 b$ & $1,4 \mathrm{~b}$ \\
\hline LA-4 & $9,6 \mathrm{a}$ & $8,5 \mathrm{a}$ & $9,3 a$ & $8,1 \mathrm{a}$ & $1,1 \mathrm{~b}$ & $0,4 \mathrm{c}$ \\
\hline$N V-1$ & $6,8 \mathrm{a}$ & $7,1 \mathrm{a}$ & $6,4 \mathrm{a}$ & $6,4 \mathrm{a}$ & $1,3 \mathrm{~b}$ & $0,6 \mathrm{c}$ \\
\hline LA-5 & $11,1 \mathrm{a}$ & $10,7 \mathrm{a}$ & $9,4 \mathrm{a}$ & $10,0 \mathrm{a}$ & $1,6 \mathrm{~b}$ & $1,0 \mathrm{c}$ \\
\hline PVA-2 & $10,9 a$ & $10,1 \mathrm{a}$ & $10,0 \mathrm{a}$ & 9,8 a & $1,0 \mathrm{~b}$ & $0,4 \mathrm{c}$ \\
\hline LA-6 & $10,6 a$ & $9,3 \mathrm{a}$ & $10,6 a$ & $9,4 \mathrm{a}$ & $1,7 \mathrm{~b}$ & $1,3 \mathrm{~b}$ \\
\hline PVA-3 & $8,2 \mathrm{a}$ & $8,6 \mathrm{a}$ & $8,2 \mathrm{a}$ & $8,0 \mathrm{a}$ & $0,8 \mathrm{~b}$ & $0,4 \mathrm{c}$ \\
\hline LV-3 & $6,5 \mathrm{a}$ & $7,2 \mathrm{a}$ & $6,3 \mathrm{a}$ & $7,0 \mathrm{a}$ & $0,7 \mathrm{~b}$ & $0,4 \mathrm{~b}$ \\
\hline LV -4 & $8,6 \mathrm{a}$ & $8,1 \mathrm{a}$ & $9,2 \mathrm{a}$ & $8,1 \mathrm{a}$ & $0,9 \mathrm{~b}$ & $0,2 \mathrm{c}$ \\
\hline PV & $8,4 \mathrm{a}$ & $8,0 \mathrm{a}$ & $7,6 \mathrm{a}$ & $7,3 \mathrm{a}$ & $1,0 \mathrm{~b}$ & $0,5 \mathrm{c}$ \\
\hline PVA-4 & $8,8 \mathrm{a}$ & $8,1 \mathrm{a}$ & $8,1 \mathrm{a}$ & $7,9 \mathrm{a}$ & $1,1 \mathrm{~b}$ & $0,4 \mathrm{c}$ \\
\hline NV-2 & $9,0 \mathrm{a}$ & 8,6 a & $8,7 \mathrm{a}$ & $8,3 \mathrm{a}$ & $1,2 \mathrm{~b}$ & $0,6 \mathrm{c}$ \\
\hline $\mathrm{RQ}-2$ & $9,2 \mathrm{a}$ & $10,2 \mathrm{a}$ & $9,1 \mathrm{a}$ & $9,1 \mathrm{a}$ & $1,7 \mathrm{~b}$ & $1,4 \mathrm{c}$ \\
\hline LVA-1 & $8,9 a$ & $9,2 \mathrm{a}$ & $10,2 \mathrm{a}$ & $8,4 \mathrm{a}$ & $1,2 \mathrm{~b}$ & $0,6 \mathrm{c}$ \\
\hline \multicolumn{7}{|c|}{ (\#)Solo alcalino } \\
\hline$C X-1$ & $7,9 \mathrm{a}$ & $7,3 \mathrm{a}$ & $8,2 \mathrm{a}$ & $7,1 \mathrm{a}$ & $1,0 \mathrm{~b}$ & $0,7 \mathrm{~b}$ \\
\hline CX-2 & $9,6 \mathrm{a}$ & $9,5 \mathrm{a}$ & $8,9 a$ & $9,2 \mathrm{a}$ & $1,8 \mathrm{~b}$ & $1,7 \mathrm{~b}$ \\
\hline LA-7 & $8,5 \mathrm{a}$ & $8,1 \mathrm{a}$ & $8,3 a$ & 7,6 a & $1,4 \mathrm{~b}$ & $0,6 \mathrm{c}$ \\
\hline LVA-2 & $9,3 \mathrm{a}$ & $8,2 \mathrm{a}$ & $9,3 \mathrm{a}$ & $8,4 \mathrm{a}$ & $1,3 b$ & $1,2 \mathrm{~b}$ \\
\hline SS & $40,5 a$ & 39,9 a & $41,8 \mathrm{a}$ & $40,2 \mathrm{a}$ & $40,7 \mathrm{a}$ & $40,5 \mathrm{a}$ \\
\hline
\end{tabular}

(†)Médias seguidas de mesma letra, nas linhas, não diferem pelo teste de Tukey a $5 \%$. (\#)Nos solos alcalinos o calcário foi substituído por gesso. 
$\mathrm{pH}$, após aplicação do composto, inferiores aos dos demais solos ácidos (Abreu Jr. et al., 2000) e do desenvolvimento de cargas negativas pelo composto ser dependente de pH (Rodela et al., 1995; Benites \& Mendonça, 1998; Oliveira, 2000).

O efeito da aplicação do composto isoladamente, sobre a CTC, não diferiu daquele causado pelo calcário + adubo, exceto naqueles solos com elevada acidez potencial inicial (solos LA-1 e PVA-3) e/ou que receberam doses de calcário geralmente acima de $1,5 \mathrm{~g} \mathrm{dm}^{-3}$ (equivalente a $3 \mathrm{t} \mathrm{ha}^{-1}$ ) (ex.: solos LA-1, LV-2, LA-3, etc.) (TABELA 1). O efeito da dose de calcário sobre a CTC está relacionado à presença, nesses solos, de minerais de argila 1:1 e de óxidos de $\mathrm{Fe}, \mathrm{Al}$ e $\mathrm{Mn}$, cujas cargas negativas são dependentes do $\mathrm{pH}$ (Raij, 1991).

O tratamento composto + calcário + adubo promoveu a maior elevação da CTC dos solos ácidos (43\% a $209 \%$ ) (TABELA 6). Esses efeitos foram superiores àqueles causados pelo tratamento composto + adubo, exceto nos solos GX, PVA-3 e LV-4, evidenciando efeito dos adubos sobre a CTC dos solos. A CTC foi obtida pela soma dos cátions trocáveis $\left(\mathrm{Ca}^{2+}\right.$, $\mathrm{Mg}^{2+}, \mathrm{K}^{+}$e Na$\left.{ }^{+}\right)$com a acidez potencial $\left(\mathrm{H}^{+}+\mathrm{Al}^{3+}\right)$ (Abreu Jr. et al., 2000) de acordo com Raij (1991).

Os resultados obtidos nos solos ácidos são concordantes com os de Melo et al. (1997), Hortenstine \& Rothwell(1972), Bengston \& Cornette (1973) e Ferro Neto (1994). Esses autores atribuíram o aumento da CTC ao acréscimo de cargas negativas provenientes da matéria orgânica contida no composto de lixo urbano. Oliveira (2000) verificou que aumentos na CTC, determinada ao $\mathrm{pH}$ atual do solo, foram relacionados diretamente com as doses de aplicação do composto e com os seus efeitos sobre o $\mathrm{pH}$. Isto também concorda com os resultados observados no presente trabalho e com aqueles verificados por Benites \& Mendonça (1998).

TABELA 6 - Capacidade de troca de cátions em solos ácidos adubados com composto de lixo, na presença e ausência de calcário dolomítico e adubos minerais, e em solos alcalinos onde o calcário foi substituído por gesso.

\begin{tabular}{|c|c|c|c|c|c|c|}
\hline \multirow{3}{*}{ Solo } & \multicolumn{4}{|c|}{ Composto de lixo } & \multirow{3}{*}{ Calcário e adubo } & \multirow{3}{*}{ Testemunha } \\
\hline & \multicolumn{2}{|c|}{ sem calcário } & \multicolumn{2}{|c|}{ com calcário } & & \\
\hline & sem adubo & com adubo & sem adubo & com adubo & & \\
\hline \multicolumn{7}{|c|}{ 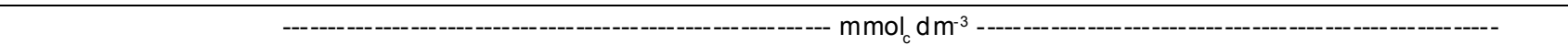 } \\
\hline \multicolumn{7}{|c|}{ Solo ácido } \\
\hline GX & $157,8 b^{\ddagger}$ & 187,8 a & $171,2 \mathrm{ab}$ & 186,9 a & $157,8 \mathrm{~b}$ & $78,2 \mathrm{c}$ \\
\hline $\mathrm{RQ}-1$ & 77,8 b & 110,6 a & 77,6 b & 106,7 a & $75,9 \mathrm{~b}$ & $42,5 \mathrm{c}$ \\
\hline LA-1 & $97,5 \mathrm{c}$ & $121,6 \mathrm{~b}$ & $124,5 b$ & $148,5 \mathrm{a}$ & $131,3 b$ & $90,8 \mathrm{c}$ \\
\hline LV-1 & $107,8 \mathrm{c}$ & $125,9 \mathrm{~b}$ & 110,4 c & $142,5 \mathrm{a}$ & $111,5 \mathrm{c}$ & $73,3 d$ \\
\hline LV-2 & $79,3 d$ & $115,7 \mathrm{c}$ & $103,8 \mathrm{c}$ & 171,9 a & $139,8 \mathrm{~b}$ & 63,7 e \\
\hline LA-2 & 79,4 c & 118,4 a & $92,3 \mathrm{~b}$ & 122,3 a & $87,9 \mathrm{bc}$ & $46,2 \mathrm{~d}$ \\
\hline PVA-1 & $80,5 \mathrm{~d}$ & $112,2 b$ & $89,2 \mathrm{~cd}$ & 135,8 a & 99,7 bc & 45,4 e \\
\hline LA-3 & $87,7 \mathrm{c}$ & $111,3 b$ & $115,1 \mathrm{~b}$ & 142,8 a & $118,8 b$ & $69,2 d$ \\
\hline LA-4 & $88,3 \mathrm{~b}$ & $111,0 \mathrm{a}$ & $95,5 \mathrm{~b}$ & $121,6 \mathrm{a}$ & 96,2 b & $65,5 \mathrm{c}$ \\
\hline$N V-1$ & $103,8 \mathrm{c}$ & $146,0 \mathrm{~b}$ & 137,2 b & $175,6 \mathrm{a}$ & $135,6 \mathrm{~b}$ & $82,7 d$ \\
\hline LA-5 & $89,1 \mathrm{~b}$ & $124,4 \mathrm{a}$ & $99,0 \mathrm{~b}$ & 134,3 a & $100,8 \mathrm{~b}$ & $47,9 \mathrm{c}$ \\
\hline PVA-2 & 82,7 bc & $112,2 \mathrm{a}$ & $90,3 \mathrm{~b}$ & $118,4 \mathrm{a}$ & $78,0 \mathrm{c}$ & $38,3 d$ \\
\hline LA-6 & $167,5 \mathrm{~b}$ & $184,5 a b$ & $179,5 b$ & 202,3 a & $167,7 \mathrm{~b}$ & $95,9 \mathrm{c}$ \\
\hline PVA-3 & $127,9 \mathrm{c}$ & $156,9 a b$ & $161,6 a b$ & $170,4 \mathrm{a}$ & $148,1 \mathrm{~b}$ & $118,8 \mathrm{c}$ \\
\hline LV-3 & $90,1 \mathrm{~b}$ & 115,9 a & $100,9 \mathrm{~b}$ & 115,7 a & $91,5 b$ & $57,9 \mathrm{c}$ \\
\hline LV-4 & $113,7 \mathrm{c}$ & $127,0 \mathrm{abc}$ & $129,2 a b$ & 139,2 a & $119,5 \mathrm{bc}$ & $92,6 \mathrm{~d}$ \\
\hline PV & $99,4 \mathrm{c}$ & 143,3 a & $123,8 b$ & 146,3 a & $124,3 \mathrm{~b}$ & $73,0 \mathrm{~d}$ \\
\hline PVA-4 & $80,3 \mathrm{c}$ & 108,7 a & $92,0 \mathrm{~b}$ & 118,4 a & $92,8 \mathrm{~b}$ & $58,9 d$ \\
\hline NV-2 & $147,7 \mathrm{~b}$ & 168,6 a & 147,4 b & 187,9 a & $168,1 \mathrm{a}$ & $128,9 \mathrm{c}$ \\
\hline $\mathrm{RQ}-2$ & $73,7 \mathrm{c}$ & $85,8 \mathrm{~b}$ & $78,1 \mathrm{bc}$ & $136,3 \mathrm{a}$ & $88,3 \mathrm{~b}$ & $50,9 d$ \\
\hline LVA-1 & $83,3 \mathrm{c}$ & 112,3 a & $98,7 \mathrm{~b}$ & 118,5 a & $94,6 \mathrm{~b}$ & $72,2 \mathrm{~d}$ \\
\hline \multicolumn{7}{|c|}{ (\#)Solo alcalino } \\
\hline$C X-1$ & 205,2 c & $223,1 \mathrm{~b}$ & $255,9 a$ & $246,0 \mathrm{a}$ & $244,5 \mathrm{a}$ & $209,0 \mathrm{bc}$ \\
\hline$C X-2$ & $492,8 a b$ & $515,7 \mathrm{ab}$ & $518,3 a b$ & $528,2 \mathrm{a}$ & $434,5 b$ & $451,2 a b$ \\
\hline LA-7 & $176,1 \mathrm{~d}$ & $187,8 \mathrm{c}$ & $202,5 b$ & $221,6 \mathrm{a}$ & $194,4 \mathrm{bc}$ & $153,8 \mathrm{e}$ \\
\hline LVA-2 & 207,6 b & 209,4 b & $241,5 a$ & $255,0 a$ & $214,7 b$ & 193,4 c \\
\hline SS & $273,1 \mathrm{~b}$ & 276,4 b & $316,7 \mathrm{a}$ & 316,5 a & 312,0 a & $242,5 \mathrm{c}$ \\
\hline
\end{tabular}

(\$)Médias seguidas de mesma letra, nas linhas, não diferem pelo teste de Tukey a $5 \%$. (\#)Nos solos alcalinos o calcário foi substituído por gesso. 
A aplicação isolada do composto de lixo também aumentou a CTC dos solos alcalinos (7\% a $15 \%$ ) (TABELA 6), excetuando-se os solos CX-1 e CX-2. Em média, não houve diferença entre os tratamentos com apenas composto e composto + adubo e entre composto + gesso e composto + gesso + adubo, respectivamente; mas houve diferença entre esses dois grupos de tratamentos, mostrando o efeito do gesso, devido ao cálcio, sobre a CTC desses solos.

Nos solos alcalinos, devido ao excesso de cátions livres em solução $\left(\mathrm{Ca}^{2+}, \mathrm{Mg}^{2+}, \mathrm{K}^{+}\right.$e $\left.\mathrm{Na}^{+}\right)$, pode-se assumir que a determinação da CTC pelo método da soma dos cátions trocáveis e acidez potencial (Raij et al., 1987; Raij, 1991) tenha conduzido a valores relativamente superestimados, porém sem invalidar os resultados obtidos.

Foi verificado incrementos na saturação por bases dos solos ácidos (TABELA 7) na ordem de $16 \%$ (solo
NV-2) a $59 \%$ (solo RQ-2), pela aplicação do composto de lixo, como conseqüência direta dos aumentos nos teores de $\mathrm{Ca}^{2+}, \mathrm{Mg}^{2+}, \mathrm{K}^{+}$e $\mathrm{Na}^{+}$e da redução da acidez potencial (Abreu Jr. et al., 2000). O efeito do composto sobre o aumento da $\mathrm{V} \%$ está diretamente relacionado com as propriedades químicas inicias dos solos (TABELA 1), notadamente do poder tampão.

Devido à forte relação entre a saturação por bases e soma de cátions trocáveis, verificou-se que os maiores efeitos sobre a $\mathrm{V} \%$ foram causados pela aplicação do composto + calcário + adubo (TABELA 7) que, à exceção dos solos LV-2 e RQ-2, não diferiram dos efeitos do tratamento composto + calcário.

Nos solos alcalinos, a aplicação do composto de lixo isoladamente elevou a saturação por bases dos solos CX-1, LA-7 e LVA-2 (TABELA 7) na ordem de $2 \%$ a $4 \%$. O menor efeito do composto sobre a saturação por bases foi decorrente da já elevada saturação por bases inicial

TABELA 7 - Saturação por bases em solos ácidos adubados com composto de lixo, na presença e ausência de calcário dolomítico e adubos minerais, e em solos alcalinos onde o calcário foi substituído por gesso.

\begin{tabular}{|c|c|c|c|c|c|c|}
\hline \multirow{3}{*}{ Solo } & \multicolumn{4}{|c|}{ Composto de lixo } & \multirow{3}{*}{ Calcário e adubo } & \multirow{3}{*}{ Testemunha } \\
\hline & \multicolumn{2}{|c|}{ sem calcário } & \multicolumn{2}{|c|}{ com calcário } & & \\
\hline & sem adubo & com adubo & sem adubo & com adubo & & \\
\hline \multicolumn{7}{|c|}{ - } \\
\hline \multicolumn{7}{|c|}{ Solo ácido } \\
\hline GX & $87,4 \mathrm{a}^{\ddagger}$ & 87,8 a & 89,8 a & 89,6 a & $79,7 \mathrm{~b}$ & $55,1 \mathrm{c}$ \\
\hline $\mathrm{RQ}-1$ & 85,6 a & 88,5 a & 85,6 a & $88,3 \mathrm{a}$ & $79,3 \mathrm{~b}$ & $67,3 \mathrm{c}$ \\
\hline LA-1 & $53,1 d$ & $62,5 \mathrm{c}$ & 85,0 a & 84,1 a & $72,4 \mathrm{~b}$ & $5,2 \mathrm{e}$ \\
\hline LV-1 & $83,7 \mathrm{a}$ & 84,3 a & 84,6 a & $87,0 \mathrm{a}$ & $73,4 \mathrm{~b}$ & $61,6 \mathrm{c}$ \\
\hline LV-2 & $60,3 \mathrm{e}$ & $67,3 d$ & $83,7 \mathrm{~b}$ & $88,7 \mathrm{a}$ & $77,4 \mathrm{c}$ & $5,7 \mathrm{f}$ \\
\hline LA-2 & $71,3 \mathrm{c}$ & $78,8 \mathrm{~b}$ & 84,1 a & 85,2 a & $73,9 \mathrm{c}$ & $16,2 d$ \\
\hline PVA-1 & $74,5 \mathrm{~d}$ & $77,9 \mathrm{c}$ & $83,1 \mathrm{~b}$ & $87,0 \mathrm{a}$ & 70,4 e & $28,0 \mathrm{e}$ \\
\hline LA-3 & $66,0 \mathrm{c}$ & $72,3 \mathrm{~b}$ & $84,6 a$ & $86,4 \mathrm{a}$ & $75,3 \mathrm{~b}$ & $27,5 d$ \\
\hline LA-4 & $80,2 \mathrm{c}$ & 81,4 bc & $84,7 a b$ & $86,0 \mathrm{a}$ & $67,7 \mathrm{~d}$ & $43,2 \mathrm{e}$ \\
\hline$N V-1$ & $73,9 \mathrm{c}$ & $81,0 \mathrm{~b}$ & $85,3 a$ & $87,3 \mathrm{a}$ & $76,6 \mathrm{c}$ & $42,3 d$ \\
\hline LA-5 & $80,4 \mathrm{c}$ & $82,8 b c$ & $85,2 \mathrm{ab}$ & $87,0 \mathrm{a}$ & $72,7 \mathrm{~d}$ & 37,7 e \\
\hline PVA-2 & $79,9 \mathrm{~b}$ & $83,5 \mathrm{a}$ & 84,5 a & $86,3 \mathrm{a}$ & $71,7 \mathrm{c}$ & $36,6 \mathrm{~d}$ \\
\hline LA-6 & $80,2 \mathrm{a}$ & 79,6 a & 85,6 a & $85,2 \mathrm{a}$ & $70,7 \mathrm{c}$ & $46,6 \mathrm{~d}$ \\
\hline PVA-3 & $47,3 \mathrm{~d}$ & $60,7 \mathrm{c}$ & $78,4 \mathrm{a}$ & 78,8 a & $66,7 \mathrm{~b}$ & $8,3 \mathrm{e}$ \\
\hline LV-3 & $74,9 \mathrm{c}$ & 79,2 b & $82,4 a b$ & $83,3 \mathrm{a}$ & $69,7 \mathrm{~d}$ & 35,3 e \\
\hline LV -4 & $71,4 \mathrm{~b}$ & $72,0 \mathrm{~b}$ & 81,8 a & 82,2 a & $66,9 \mathrm{c}$ & $36,7 d$ \\
\hline PV & $77,8 \mathrm{c}$ & $83,3 \mathrm{~b}$ & $85,5 a b$ & 87,1 a & $76,4 \mathrm{c}$ & $47,3 d$ \\
\hline PVA-4 & $72,5 \mathrm{c}$ & $76,1 \mathrm{~b}$ & $81,9 a$ & $84,1 \mathrm{a}$ & $67,6 \mathrm{~d}$ & $25,5 \mathrm{e}$ \\
\hline NV-2 & $83,2 \mathrm{a}$ & 83,7 a & $84,3 \mathrm{a}$ & $86,5 \mathrm{a}$ & $74,9 \mathrm{~b}$ & $66,9 \mathrm{c}$ \\
\hline $\mathrm{RQ}-2$ & $68,6 \mathrm{~cd}$ & $70,9 \mathrm{c}$ & $78,6 \mathrm{~b}$ & $85,9 a$ & $66,8 \mathrm{~d}$ & $10,0 \mathrm{e}$ \\
\hline LVA-1 & $63,1 \mathrm{c}$ & $69,4 \mathrm{~b}$ & $80,2 \mathrm{a}$ & 79,9 a & $59,3 d$ & $13,8 \mathrm{e}$ \\
\hline \multicolumn{7}{|c|}{ (\#)Solo alcalino } \\
\hline$C X-1$ & $91,3 d$ & $91,9 \mathrm{c}$ & 93,2 a & $92,6 \mathrm{~b}$ & 89,3 e & $87,4 f$ \\
\hline CX-2 & $98,0 \mathrm{a}$ & $97,9 a b$ & 98,1 a & $98,0 \mathrm{a}$ & 97,4 b & $97,6 a b$ \\
\hline LA-7 & $93,5 \mathrm{~b}$ & $93,2 \mathrm{~b}$ & 94,3 a & $94,3 \mathrm{a}$ & $91,3 \mathrm{c}$ & $89,8 d$ \\
\hline LVA-2 & $94,9 \mathrm{~b}$ & 94,6 b & 95,7 a & 95,7 a & $93,6 \mathrm{c}$ & $93,3 \mathrm{c}$ \\
\hline SS & $96,6 \mathrm{abc}$ & $96,3 \mathrm{bc}$ & $97,1 \mathrm{a}$ & $96,8 a b$ & $96,6 \mathrm{abc}$ & $96,1 \mathrm{c}$ \\
\hline
\end{tabular}

(‡)Médias seguidas de mesma letra, nas linhas, não diferem pelo teste de Tukey a 5 \%. (\#)Nos solos alcalinos o calcário foi substituído por gesso. 
desses solos (TABELA 1). Assim como ocorreu com os teores de cálcio trocável, o gesso aplicado conjuntamente com o composto conduziu aos maiores efeitos sobre a saturação por bases.

\section{CONCLUSÕES}

A aplicação do composto de lixo urbano promoveu a elevação dos teores dos cátions trocáveis, da capacidade de troca de cátions e da saturação por bases de modo equivalente ou superior às aplicações de calcário com adubos minerais nos solos ácidos e de gesso com adubos minerais nos solos alcalinos.

O potássio contido no composto apresentou equivalência com o do cloreto de potássio e o cálcio e magnésio contidos no composto, equivalência com os do calcário.

O uso agrícola do composto de lixo, como fertilizante orgânico, é viável do ponto de vista técnico, social e ambiental; todavia seus efeitos sobres as propriedades químicas do solo devem ser mantidos sob monitoramento constante.

\section{AGRADECIMENTOS}

À FAPESP pela concessão de bolsa de doutorado ao primeiro autor e ao Dr. Hélio do Prado, pesquisador científico do Instituto Agronômico de Campinas, pela identificação das amostras dos solos conforme o sistema brasileiro de classificação de solos (Embrapa, 1999).

\section{REFERÊNCIAS BIBLIOGRÁFICAS}

ABREU JR., C.H.; MURAOKA, T.; LAVORANTE, A.F.; ALVAREZ V., F.C. Condutividade elétrica, reação do solo e acidez potencial em solos adubados com composto lixo. Revista Brasileira de Ciência do Solo, v.24, p.635-647, 2000.

AVNIMELECH, Y.; KOCHBA, M.; YOTAL, Y.; SHKEDI, D. On the use of municipal solid waste for the reclamation of saline and alkaline soils. In: INTERNATIONAL CONGRESS OF SOIL SCIENCE, 14., Kyoto, 1990. Transactions. Kyoto: ISSS, 1990. p.186-191.

AVNIMELECH, Y.; SHKEDI, D.; KOCHBA, M.; YOTAL, Y. The use of compost for the reclamation of saline and alkaline soils. Compost Science and Utilization, v.2, p.6-11, 1994.

BENGSTON, G.W.; CORNETTE, J.J. Disposal of composted municipal waste in a plantation of young slash pine: Effects on soil and trees. Journal of Environmental Quality, v.2, p.441-444, 1973.

BENITES, V.M.; MENDONÇA, E.S. Propriedades eletroquímicas de um solo eletropositivo influenciadas pela adição de matéria orgânica. Revista Brasileira de Ciência do Solo, v.22, p.215221, 1998

BERTON, R.S.; VALADARES, J.M.A.S. Potencial agrícola do composto de lixo urbano no Estado de São Paulo. 0 Agronômico, v.43, p.87-93, 1991.

BOAVENTURA, G.R.; SANTOS, A.R.; PINELLI, M.P.; DIAS, R.P. Metodologia analítica para a determinação dos metais pesados em compostos de lixo urbano usando espectrometria de emissão atômica com plasma e espectrometria de absorção atômica. In: CONGRESSO BRASILEIRO DE CIÊNCIA DO SOLO, 25., Viçosa. Resumos expandidos. Viçosa: SBCS; UFV, 1995. p.2306-2308.
CRAVO, M.S. Composto de lixo urbano como fonte de nutrientes e metais pesados para alface. Piracicaba, 1995. 148p. Tese (Doutorado) - Escola Superior de Agricultura "Luiz de Queiroz", Universidade de São Paulo.

CRAVO, M.S.; MURAOKA, T.; GINE-ROSIAS, M.F.G. Caracterização química de compostos de lixo urbano de algumas usinas brasileiras. Revista Brasileira de Ciência do Solo, v.22, p.547-553, 1998.

EMPRESA BRASILEIRA DE PESQUISA AGROPECUÁRIA. Centro Nacional de Pesquisa de Solos. Sistema brasileiro de classificação de solos. Brasília: Embrapa Produção de Informação; Rio de Janeiro: Embrapa Solos, 1999. 412p.

FASSBENDER, H.W. Química de suelos, con énfasis en suelos de américa latina. Turrialba: Instituto Interamericano de Ciências Agrícolas de la OEA, 1975. 398p.

FERRO NETO, A. Produção racional de composto de lixo urbano. In: SEMINÁRIO SOBRE USO DE RESÍDUOS INDUSTRIAIS E URBANOS EM FLORESTAS, 1., Botucatu, 1994. Trabalhos apresentados. Botucatu: UNESP, 1994. p.1-14.

HAAN, S. Results of municipal waste compost research over more than fifty years at the Institute for Soil Fertility at haren Groningen. Netherlands Journal of Agricultural Science, v.29, p.49-61, 1981.

HORTENSTINE, C.C.; ROTHWELL, D.F. Use of municipal compost in reclamation of phosphate - mining sand tailings. Journal of Environmental Quality, v.1, p.415-418, 1972.

KIEHL, E.J. Fertilizantes orgânicos. Piracicaba: Agronômica Ceres, 1985. 492p.

LIMA, J.S.; LICHTIG, J.; OLIVEIRA E.; MENK, J.R.F. Hortaliças cultivadas com composto orgânico de lixo urbano não apresentam contaminação com metais pesados. Revista Ceres, v.46, p.571-585, 1999.

MALAVOLTA, E. Manual de química agrícola: nutrição de plantas e fertilidade do solo. Piracicaba: Agronômica Ceres, 1976. 528p.

MAZUR, N.; VELLOSO, A.C.X.; SANTOS, G.A. Efeito do composto de resíduo urbano no $\mathrm{pH}$ e alumínio trocável em solos ácidos. Revista Brasileira de Ciência do Solo, v.7, p.157-159, 1983.

MELO,W.J.; MARQUES, M.O.; SILVA, F.C.; BOARETTO, A.E. Uso de resíduos sólidos urbanos na agricultura e impactos ambientais (Compact disc). In: CONGRESSO BRASILEIRO DE CIÊNCIA DO SOLO, 26., Rio de Janeiro, 1997. Anais. Rio de Janeiro: Embrapa; SBCS, 1997.

OLIVEIRA, F.C. Disposição de lodo de esgoto e composto de lixo urbano num latossolo vermelho-amarelo cultivado com cana-de-açúcar. Piracicaba, 2000. 247p. Tese (Doutorado) Escola Superior de Agricultura "Luiz de Queiroz", Universidade de São Paulo.

RAIJ, B.van. Fertilidade do solo e adubação. Piracicaba: Agronômica Ceres, 1991. 343p.

RAIJ, B.van; QUAGGIO, J.A.; CANTARELLA, H.; FERREIRA, M.E.; LOPES, A.S.; BATAGLIA, O.C. Análise química do solo para fins de fertilidade. Campinas: Fundação Cargill, 1987. 170p.

RODELA, A.A.; FISCHER, K.R.; ALCARDE, J.C. Cation exchange capacity of an acid soil as influenced by different sources of organic matter. Communications in Soil Science and Plant Analysis, v.26, p.17-18, 1995.

SANTOS, R.V. Correção de um solo Salino-Sódico e absorção de nutrientes pelo feijoeiro vigna (Vigna unguiculata (L.) Walp.). Piracicaba, 1995. 120p. Tese (Doutorado) - Escola Superior de Agricultura "Luiz de Queiroz", Universidade de São Paulo. 
SANTOS, R.V.; MURAOKA, T. Interação salinidade e fertilidade do solo In: GHEYI, H.R.; QUEIROZ, J.E.; MEDEIROS, J.F. (Ed.) Manejo e controle da salinidade na agricultura irrigada. Campina Grande: UFPB, 1997. p.289-317.

SAS INSTITUTE. SAS-Statistical analysis system (software). Cary: Statistical Analysis System, 1998.

TRINDADE, A.V.; VILDOSO, C.I.A.; MUCHOVEJ, R.M.C.; COSTA, L.M. Interação de composto de lixo urbano e fungos micorrízicos na nutrição e crescimento do milho. Revista Brasileira de Ciência do Solo, v.20, p.199-208, 1996.
XIN, T.H.; TRAINA, S.J.; LOGAN, T.J. Chemical properties of municipal solid waste compost. Journal of Environmental Quality, v.21, p.318-329, 1992.

ZONTA, E.P.; MACHADO, A.A.; SILVEIRA JR., P. Sistemas de análise estatística para microcomputadores: manual de utilização. Pelotas, 1987. 145p.

$\overline{\text { Recebido em } 31.07 .00}$ 